\title{
Mortality risks of body mass index and energy intake trajectories in institutionalized elderly people: a retrospective cohort study
}

Yoshiaki Kawakami ${ }^{*}$ (D) and Jun Hamano²

\begin{abstract}
Background: Many factors can identify the mortality risks of institutionalized elderly people; among all such factors, body mass index (BMI) and energy intake (EI) can be employed as independent predictors. The objective of this study was to elucidate about the mortality risks and the trajectory of two parameters obtained from continuously monitored data.
\end{abstract}

Methods: This retrospective cohort study targeted 218 elderly people who were admitted to a nursing home for at least 6 months between 2007 and 2020 and passed away at the nursing home. BMl and El (kcal) per body weight (BW) were continuously measured until death.

Results: BMI continued to decrease for 5 years until death. The rate of change of BMI significantly increased for 3 years before death $(P=0.004)$. In contrast, the rate of change of El per BW significantly increased after 1 year before death $(P<0.001)$; in addition, 2 months before death, this rate of change significantly exceeded that of $\mathrm{BMI}(P=$ 0.007). In the four risk groups that were examined, a BMI of $<18.0+$ El per BW of $<29.2$ and a BMl of $<17.3+$ El per BW of $<28.3$ were significantly correlated with a high risk of death (log-rank test: $P<0.001, P=0.002$, respectively). There was no significant difference in the hazard ratio based on the age at the time of admission; however, when El per BW was $<23.8$, the risk of death was significantly higher [hazard ratio $=4.36 ; 95 \%$ confidence interval: $2.31-8.24$ ].

Conclusions: Elderly people in the current study presented a tendency toward decreasing BMI starting 60 months prior to death even if El per BW remained constant. In the 1 year before death, El per BW rapidly decreased. When the rate of change of El per BW exceeded the rate of decrease of BMI, it was considered to be the point of no return when death was imminent. Our study showed that identifying mortality risks from the relationship between the trajectories of the two parameters that were continuously measured for several months to years is possible.

Keywords: Body mass index, Mortality, Elderly, Energy intake, Long-term care, Unintentional weight loss

*Correspondence: y-kawakami@tau.ac.jp

1 Department of Nursing, Tokyo Ariake University of Medical and Health Sciences, Tokyo, Japan

Full list of author information is available at the end of the article

\section{Background}

Although many families of elderly people and experts in the field of elderly care believe that palliation is an important goal for institutionalized elderly people, elderly people who pass away in a facility do not receive ideal palliative care [1]. It is possible that because advanced dementia and debility, when not specified otherwise, are 
not considered terminal conditions, care might not be directed toward optimum comfort until death is acknowledged as being imminent [2, 3]. Family members providing care are not receptive of the idea that their relatives are in the dying phase, whereas healthcare professionals do not communicate definitive evidence indicative of the approaching death. This is a hindrance to palliative care [4-7].

Therefore, it is extremely important to make an accurate risk assessment of the prognosis and imminent death. Mortality prediction and risk assessment of elderly people requires the analysis of many factors, such as blood parameters, the number of comorbidities, immune dysfunctions, and conducting statistical approaches [810]. However, such data collection and evaluation require skilled personnel, a multidisciplinary approach, and in some cases, high costs. Thus, the necessary data may not be available for institutionalized elderly people such as those admitted to a nursing home (NH) or in a homecare setting [7]. Factors for mortality prediction and risk assessment include specific causes and the number of comorbidities; however, institutionalized elderly people usually have multiple morbidities [11] but do not receive a routine workup, making it difficult to identify the true cause of their death [12].

Nutritional status is significantly or independently associated with mortality [13-15]. Therefore, the mortality risks associated with nutritional status could be used to predict mortality on their own. However, institutionalized elderly people with dementia experience mental and cognitive impairments, psychological conditions, and dysphagia, presenting complex nutritional problems in the early stage of death $[16,17]$; thus, even if mortality was predicted, predicting the timing of death would be difficult.

Many studies have shown that a decrease in body weight (BW) and body mass index (BMI) increases the risk of mortality [18-22]. It has particularly been verified that unintentional weight loss in elderly people increases the risk of death [23]. According to our 5-year longitudinal study of 106 elderly people who were admitted to and died in an $\mathrm{NH}$, even if the energy intake (EI) remained constant, BMI started to gradually decrease 5 years prior to death, and EI significantly decreased several months prior to death [24]. In other words, when the trajectory of EI rapidly decreases compared with the trajectory of decreasing BMI, it is reasonable to consider it as the "point of no return," where death is imminent. An evaluation of the relationship between the two trajectories might be a useful tool in identifying mortality risks.

Thus, this study aimed to understand the mortality risks by elucidating about the relationship between the trajectory of BMI and the trajectory of EI, which are parameters that could be routinely monitored for institutionalized elderly people, to determine whether they could be used to make an accurate mortality prediction and risk assessment for elderly people.

\section{Methods}

\section{Study Design and Participants}

The present study was a single-center retrospective cohort study. Baseline data collection was conducted from April 1, 2007 to February 29, 2020. The subjects were all elderly individuals (aged $\geq 65$ years) who died during this period in "Junseien," which is an NH for the Elderly, located in Kanagawa Prefecture in Japan. They were officially identified as being in a state requiring long-term care according to the Public Nursing Care Insurance Law. Residents of a facility covered by the Public Nursing Care Insurance, such as this $\mathrm{NH}$, are required to be officially recognized as being at the care-need level 3 or above as per the Long-Term Care Insurance system.

The clinical picture of care-need level 3 individuals is as follows: difficulty in rising, moving, and transferring to and from a vehicle on their own, understanding the routine schedule [25], and remembering what they were doing prior to an interview. At the highest level, careneed level 5, in addition to the abovementioned conditions, includes dysphagia, disorientation, limited range of motion in the joints, motor paralysis, and other problems $[26,27]$.

All subjects received professional care assistance under the same living conditions from the time of admission. They consumed three main meals (breakfast, lunch, and dinner) that were managed as per their EI (kcal) and nutrient requirements by registered dieticians of the facility at a given time. All their meals were cooked and arranged at the facility. If they had difficulty in eating or swallowing, they received assistance.

The subjects included elderly individuals who continuously resided in the $\mathrm{NH}$ for at least 6 months and who passed away during their stay without receiving artificial nutrition and hydration (ANH). The exclusion criterion was elderly individuals who died after being hospitalized due to acute diseases or symptoms requiring continuous medical care that the $\mathrm{NH}$ could not provide.

Among the 267 individuals who passed away at the $\mathrm{NH}$ during the survey period, 218 met the inclusion criteria and were included in the present study.

\section{Clinical Measurements}

Nurses and trained caregivers measured the height of all elderly individuals to $0.1 \mathrm{~cm}$ and BW to $0.1 \mathrm{~kg}$ following a standard protocol [28] within 72 hours after admission and every month thereafter. For those with difficulty in 
Table 1 Baseline clinical characteristics of the 218 elderly people by the survival duration (months)

\begin{tabular}{|c|c|c|c|c|c|c|c|c|c|c|c|c|c|}
\hline & \multicolumn{3}{|c|}{6 to $<12$ months } & \multicolumn{3}{|c|}{12 to $<36$ months } & \multicolumn{3}{|c|}{36 to $<60$ months } & \multicolumn{3}{|c|}{$\geq 60$ months } & \multirow[t]{2}{*}{$P$-value * } \\
\hline & $n=29$ & & & $n=8$ & & & $n=5$ & & & $n=5$ & & & \\
\hline Age at admission (years) & 87 & \pm & 6 & 86 & \pm & 8 & 86 & \pm & 8 & 85 & \pm & 7 & 0.9091 \\
\hline Age at death (years) & 87 & \pm & 7 & 88 & \pm & 8 & 90 & \pm & 8 & 91 & \pm & 7 & 0.0205 \\
\hline Women (\%) & 59 & & & 78 & & & 83 & & & 90 & & & 0.0105 \\
\hline Height (cm) & 156 & \pm & 9 & 152 & \pm & 8 & 150 & \pm & 8 & 150 & \pm & 7 & 0.0022 \\
\hline BW (kg) & 44.6 & \pm & 7.5 & 42.7 & \pm & 8.3 & 42.4 & \pm & 8.2 & 45.9 & \pm & 9.0 & 0.1003 \\
\hline $\mathrm{BMI}\left(\mathrm{kg} / \mathrm{m}^{2}\right)$ & 18.3 & \pm & 2.7 & 18.5 & \pm & 3.0 & 18.8 & \pm & 2.7 & 20.5 & \pm & 3.9 & 0.0022 \\
\hline El (kcal/day) & 1,055 & \pm & 345 & 1,256 & \pm & 235 & 1,241 & \pm & 271 & 1,385 & \pm & 191 & $<0.0001$ \\
\hline El per BW (kcal/kg/day) & 24.0 & \pm & 8.2 & 30.3 & \pm & 7.6 & 29.8 & \pm & 6.8 & 31.2 & \pm & 6.8 & 0.0003 \\
\hline
\end{tabular}

Data are the mean \pm standard deviation or $\mathrm{n}(\%)$

${ }^{*} P$-value for one-way analysis of variance. Sex was analyzed using the Fisher's exact test

$B M I$ Body mass index, BW Body weight, El energy intake

standing up straight, the height was measured to $0.1 \mathrm{~cm}$ using a measuring tape and the weight was measured using a wheelchair scale.

A registered dietitian calculated the calorie count for each meal for each subject and placed the meal on an individual tray. Upon completion of each meal, the trained caregivers observed and recorded the proportion of meals consumed on a scale of 1-10. EI (kcal) was calculated daily by multiplying the proportion of the meal consumed by the nutritional value of each meal.

\section{Statistical Analysis}

The participants of this study were divided into four groups: 6 months to $<12$ months, 12 months to $<36$ months, 36 months to $<60$ months, and $>60$ months based on the number of months they survived following their admission. Because the age at admission and death, sex, height/weight at admission, BMI, mean EI per day 1 month after admission, and daily EI per BW, which also had an impact on survival $[29,30]$, were used to evaluate the energy consumption of the elderly people who stayed in a long-term care setting for a long period of time, we calculated the mean EI per BW and checked for statistically significant differences using one-way analysis of variance.

Furthermore, up to 60 months immediately before death, we calculated the mean monthly BMI and the mean daily EI per BW for every month. Later, we calculated the rate of change compared with the mean value 6 months ago. For each rate of change, we checked for statistically significant differences in the rate of change over 12 months (every 12 months from 60 months prior to death) using the paired $t$-test. This was followed by a verification of the change in the mean rate of change between the two parameters for each month during the 12 months prior to death.

Finally, based on BMI and EI per BW data from 12 months and 6 months prior to death, we divided the subjects into four groups at the time of admission, plotted Kaplan-Meier curves, and performed associated logrank tests. Risk factors for mortality were assessed using the Cox proportional hazards regression model and associations were presented as hazard ratios (HRs) and 95\% confidence intervals (CIs).

A $P$-value of $<0.05$ was considered statistically significant. All statistical analyses were performed using JMP Pro 15.2.0 (for Windows 10) (SAS Institute Inc., Cary, NC, USA).

\section{Results}

The baseline characteristics of the 218 elderly people are presented in Table 1. Subjects were divided into four groups: survival of 6 months to $<12$ months, 12 months to $<36$ months, 36 months to $<60$ months, and $>60$ months. There was a significant difference in the age at death, sex, height, BMI, EI, and EI per BW (Table 1).

The trends observed for the two parameters and the relationship between them were determined (Fig. 1).

Table 2 shows the difference in the rate of change of BMI and EI per BW for $60-48$ months prior to death, 48-36 months prior to death, 36-24 months prior to death, 24-12 months prior to death, and 12 months to immediately prior to death. BMI continuously decreased for 60 months prior to death, but its decrease was significant from 36 months prior to death. There was no significant change in EI per BW until 12 months prior to death, following which there was a significant decrease in this parameter immediately before death. 


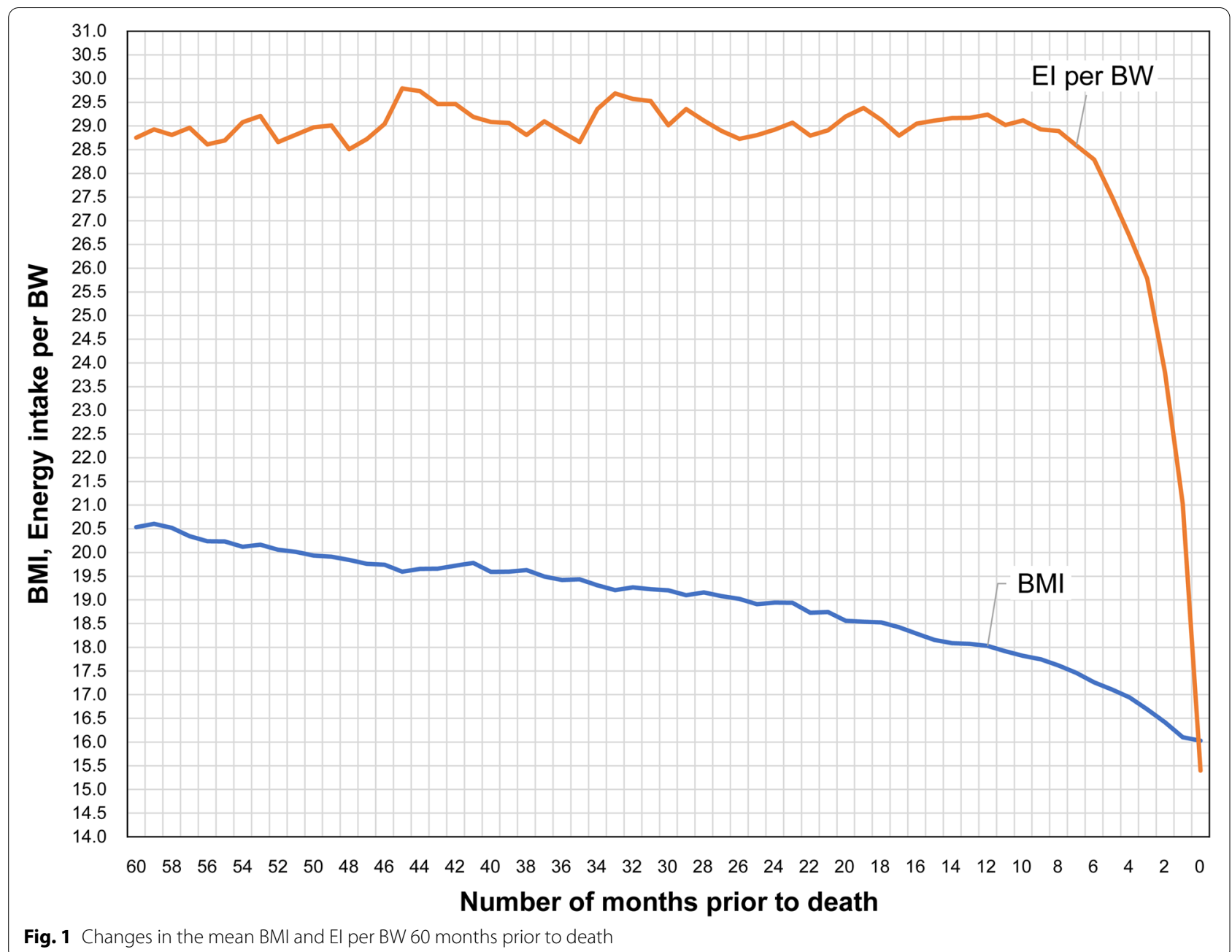

Table 2 Difference in the rate of change in BMI and El per BW every 12 months from 60 months prior to death

\begin{tabular}{|c|c|c|c|c|c|c|}
\hline \multirow[b]{2}{*}{$\begin{array}{l}\text { Months prior to } \\
\text { death }\end{array}$} & \multicolumn{3}{|l|}{ BMI } & \multicolumn{3}{|l|}{ El per BW } \\
\hline & Mean difference & SD & $P$-value* & Mean difference & SD & $P$-value* \\
\hline $60-48$ & -0.26 & 0.25 & 0.2907 & -0.76 & 0.68 & 0.2666 \\
\hline $48-36$ & -0.24 & 0.17 & 0.1692 & 0.27 & 0.68 & 0.6915 \\
\hline $36-24$ & -0.44 & 0.15 & 0.0042 & -0.18 & 0.63 & 0.7822 \\
\hline $24-12$ & -0.94 & 0.15 & $<0.0001$ & 0.00 & 0.49 & 0.9931 \\
\hline 12-prior to death & -2.20 & 0.26 & $<0.0001$ & -13.21 & 1.22 & $<0.0001$ \\
\hline
\end{tabular}

${ }^{*} P$-value for paired-sample t-test

$B M I$ Body mass index, BW Body weight, El Energy intake

We obtained the difference between the rates of change of the two parameters, BMI and EI per BW, for each month from 12 months prior to death in Table 3. After EI per BW began to decrease 7 months prior to death, and particularly in the 4 months prior to death, when the decrease in EI per BW exceeded that of BMI, we verified this change using the paired $t$-test. The mean rate of change of EI per BW that exceeded that of BMI 4 months prior to death continued to decrease and was significantly higher than that of BMI 2 months prior to death.

BMI and EI per BW were 18.0 and 29.2, respectively, at 12 months prior to death and 17.3 and 28.3 , respectively, 
Table 3 Rate of change of BMI and El per BW for each month from 12 months prior to death

\begin{tabular}{|c|c|c|c|c|c|c|c|}
\hline \multirow[b]{2}{*}{$\begin{array}{l}\text { Months prior to } \\
\text { death }\end{array}$} & \multirow[b]{2}{*}{ Mean } & \multicolumn{2}{|l|}{ BMI } & \multicolumn{4}{|c|}{ El per BW } \\
\hline & & $\begin{array}{l}\text { Mean rate of } \\
\text { change }\end{array}$ & SD & Mean & $\begin{array}{l}\text { Mean rate of } \\
\text { change }\end{array}$ & SD & $P$-value* \\
\hline 12 & 18.0 & 0.970 & 0.069 & 29.2 & 1.020 & 0.224 & 0.0117 \\
\hline 11 & 17.9 & 0.971 & 0.062 & 29.0 & 1.038 & 0.305 & 0.0111 \\
\hline 10 & 17.8 & 0.974 & 0.060 & 29.1 & 1.015 & 0.187 & 0.0147 \\
\hline 9 & 17.7 & 0.972 & 0.060 & 28.9 & 1.011 & 0.244 & 0.0477 \\
\hline 8 & 17.6 & 0.971 & 0.063 & 28.9 & 1.015 & 0.323 & 0.0676 \\
\hline 7 & 17.5 & 0.965 & 0.067 & 28.6 & 0.988 & 0.202 & 0.1569 \\
\hline 6 & 17.3 & 0.959 & 0.065 & 28.3 & 0.978 & 0.193 & 0.2033 \\
\hline 5 & 17.1 & 0.953 & 0.072 & 27.5 & 0.973 & 0.268 & 0.3364 \\
\hline 4 & 16.9 & 0.951 & 0.069 & 26.7 & 0.944 & 0.242 & 0.6511 \\
\hline 3 & 16.7 & 0.943 & 0.077 & 25.8 & 0.932 & 0.303 & 0.5732 \\
\hline 2 & 16.4 & 0.935 & 0.077 & 23.8 & 0.865 & 0.359 & 0.0074 \\
\hline 1 & 16.1 & 0.926 & 0.086 & 21.0 & 0.774 & 0.368 & $<0.0001$ \\
\hline Prior to death & 16.0 & 0.921 & 0.093 & 15.4 & 0.594 & 0.395 & $<0.0001$ \\
\hline
\end{tabular}

${ }^{*} P$-value for paired-sample t-test

$B M I$ Body mass index, BW Body weight, EI Energy intake, SD Standard deviation

at 6 months prior to death. Based on these data, we divided subjects into four groups, namely, those whose scores were the same or above the mean and those whose scores were below the mean at the time of admission; plotted the Kaplan-Meier curves; and performed associated log-rank tests. In the group with BMIs of $<18.0$ and EIs per BW of $<29.2$ and the group with BMIs of $<17.3$ and EIs per BW of $<28.3$, the survival rate decreased significantly (Fig. 2).

Finally, based on the sex and age at the time of admission and values obtained from each mean of BMI and EI per BW at 12, 6, and 2 months prior to death, we created four categories of $\mathrm{BMI}-<16.4,16.4$ to $<17.2$, 17.3 to $<17.9$, and $\geq 18$ - and four categories of EI per BW- $<23.8,23.8$ to $<28.2,28.3$ to $<29.2$, and $\geq 29.2$ - and obtained the HRs and their 95\% CIs using the Cox proportional hazards model (Table 4).

The results showed that the male subjects had an HR of 1.77 (95\% CI: 1.24-2.53), indicating that the risk of death was 1.77 times significantly higher than that for the female subjects. The group with a BMI of $<16.4$ had an HR of 1.73 (95\% CI: 1.17-2.55), indicating that compared with the group with a BMI of $\geq 18.0$, the risk of death was 1.73 times significantly higher. The group with a BMI of 16.4 to $<17.2$ had an HR of 2.02 (95\% CI: $1.25-3.26$ ), indicating that the risk of death was 2.02 times significantly higher than that of the group with a BMI of $\geq 18.0$.

When the EI per BW was $<23.8 \mathrm{kcal} / \mathrm{kg}$, the HR was 4.36 (95\% CI: 2.31-8.24), indicating that the risk of death was 4.36 times significantly higher than that when EI per
BW was $\geq 29.2 \mathrm{kcal} / \mathrm{kg}$. Comparisons based on the age at the time of admission did not present significant HRs.

\section{Discussion}

To our knowledge, this is the first study to have deciphered the trajectories that longitudinally examined BMI for each month until death and calculated EI per BW from three daily meals during these months (up to 5 years prior to death) for elderly people who died at an $\mathrm{NH}$.

The most notable finding in this study was that the changes of BMI and EI per BW showed distinctive trajectories over time as subjects came closer to their death.

BMI of elderly people who died at the $\mathrm{NH}$ gradually decreased from 60 months prior to death and continued to decrease until death. The mean BMI at 60 months prior to death was 20.5, but the mean BMI immediately prior to death was 16.0. In a cross-sectional survey, a BMI of 20.0 was considered a valid threshold for determining a high risk for short-term mortality in elderly individuals [21, 31]. Furthermore, the World Health Organization classifies adults aged $\geq 20$ with BMIs $<18.5$ as being underweight. The mean BMI of the elderly subjects in this study was $<20.0$ at 50 months prior to death and was $<18.5$ at 17 months prior to death, clearly continuing to follow a decreasing trajectory. Therefore, by analyzing not only the specific value of BMI but also its trajectory for several months to years, the long-term mortality risk over a longer span (i.e., years) could be determined.

EI per BW of elderly people did not show any significant change in trend until 12 months prior to death. EI 

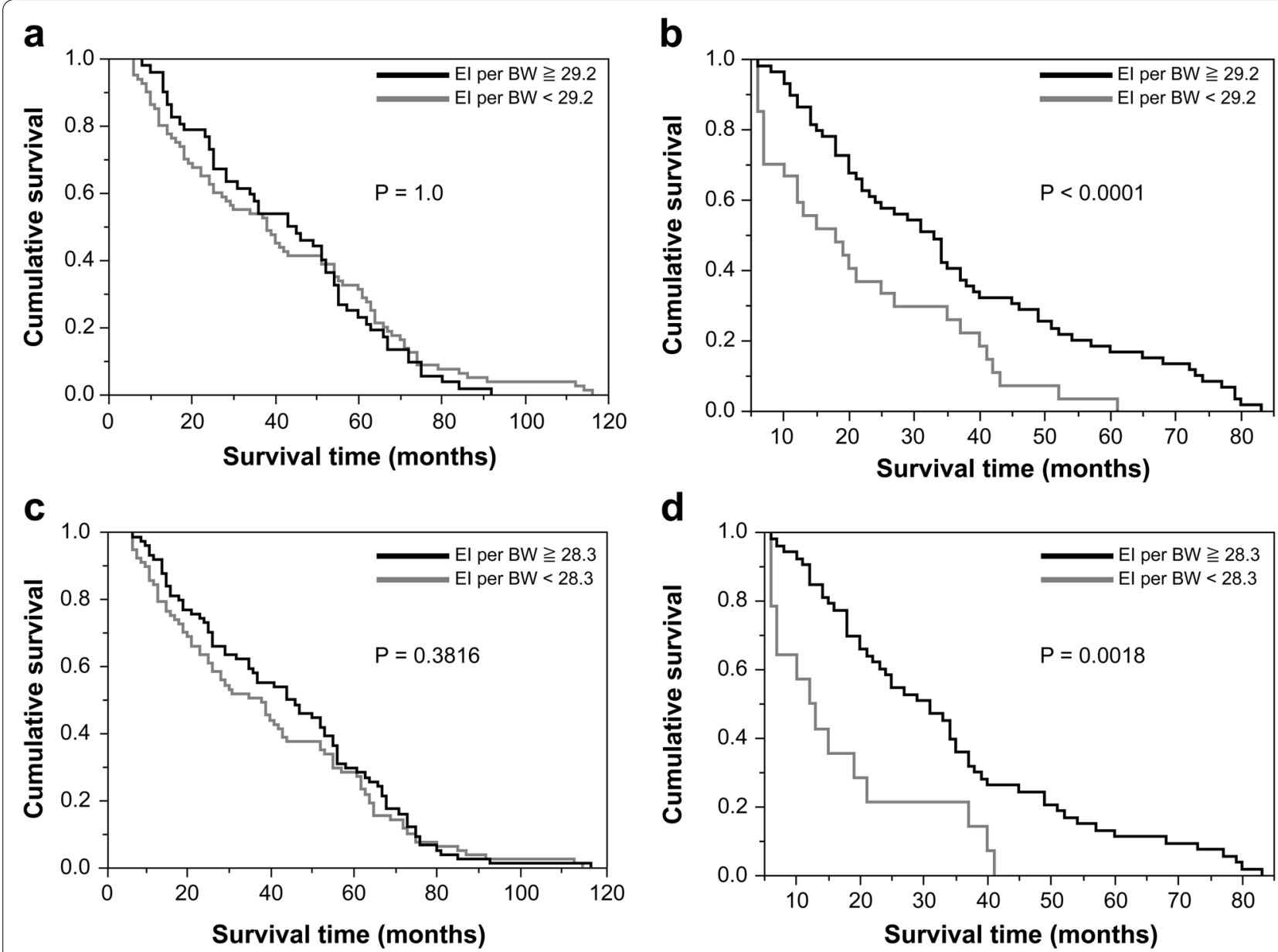

Fig. 2 Survival curves from the time of admission. a BMI $\geq 18.0$ Groups with El per BW $\geq 29.2(n=80)$ and of $<29.2(n=52)$ b BMI $<18.0 \mathrm{Groups}$ with El per BW $\geq 29.2(n=59)$ and of $<29.2(n=27) \mathbf{c ~ B M I} \geq 17.3$ Groups with El per BW $\geq 28.3(n=74)$ and of $<28.3(n=77)$ d BMl $<17.3 \mathrm{Groups}$ with El per BW $\geq 28.3(n=53)$ and $<28.3(n=14)$

per BW began to decrease at 7 months prior to death, then followed an irreversible decreasing trend. Low EI per BW is implicated in mortality and is an independent predictor of all-cause mortality [32]. If BMI is useful in identifying the long-term mortality risk, a rapid decrease in the trajectory of EI per BW and a change in its value to $<23.8$ represents a short-term mortality risk within several months, which is a useful indicator.

The second important finding was that the trajectories of the changes in BMI and EI per BW do not decrease in parallel at similar rates of change.

At 60 months prior to death, BMI showed a decreasing trajectory, but EI per BW either continued to increase until 12 months prior to death or did not show continuous decrease, not presenting a notable difference in the rate of change. EI per BW for the subjects in the present study at 12 months prior to death was $29.2 \mathrm{kcal} / \mathrm{BW}$, which was higher than $23.6-23.8 \mathrm{kcal} / \mathrm{BW}$ calculated based on the Harris-Benedict equation for calories that are necessary for each day [33]. In other words, despite the intake of the required amount of calories, BW continued to decrease. The rate of change of EI per BW was greater than BMI at 4 months prior to death and significantly more than the rate of change of BMI at 2 months prior to death. Therefore, following a long-term BMI loss and stable EI per BW, a relationship wherein the depletion of EI per BW increases faster than the declined in BMI indicates an imminent death.

In past studies, BMI was examined [31, 34, 35] as a factor related to mortality [36, 37] and malnutrition, and mortality was discussed based on BMI measured at a point in time. However, our study showed that by continuously measuring BMI and EI and examining the resulting trajectories and their relationship, instead of treating each parameter as a separate predictor, mortality risks could be identified with more accuracy. Risk assessment based on the relationship between the trajectories of BMI 
Table 4 Characteristics of subjects and hazard ratios and 95\% confidence intervals for each factor

\begin{tabular}{llllll}
\hline Characteristics & Hazard ratio & \multicolumn{2}{l}{$\begin{array}{l}\text { 95\% confidence } \\
\text { interval }\end{array}$} & P-value \\
\hline Sex & & & & \\
\multicolumn{1}{l}{ Age (years) } & Male & 1.77 & 1.24 & 2.53 & 0.0016 \\
& $<74$ & 1.00 & 0.51 & 1.95 & 0.9967 \\
& $75-84$ & 0.69 & 0.42 & 1.14 & 0.1482 \\
& $85-94$ & 0.87 & 0.54 & 1.41 & 0.5687 \\
& $>95$ & 1 & Reference & & \\
sBMl & & & & & \\
& $<16.4$ & 1.73 & 1.17 & 2.55 & 0.0057 \\
& $16.4-17.2$ & 2.02 & 1.25 & 3.26 & 0.0042 \\
& $17.3-17.9$ & 1.14 & 0.69 & 1.90 & 0.6028 \\
& $>18$ & 1 & Reference & & \\
El per BW & & & & & \\
& $<23.8$ & 4.36 & 2.31 & 8.24 & $<0.0001$ \\
& $23.8-28.2$ & 1.18 & 0.85 & 1.65 & 0.3180 \\
& $28.3-29.2$ & 1.11 & 0.63 & 1.95 & 0.7229 \\
& $>29.2$ & 1 & Reference & & \\
\hline
\end{tabular}

$B M I$ Body mass index, $B W$, Body weight, El Energy intake

and EI per BW is an effective way of detecting mortality among institutionalized elderly individuals.

An interesting aspect of the present study is that by examining the relationship between the trajectories of the two parameters, it is possible to evaluate the timeimminent risk of death. When the rate of change of BMI significantly decreases while that of EI per BW does not, mortality risks tend to increase within 3 years. Under long-term BMI loss, when the nutritional depletion becomes evident and the rate of change of EI per BW significantly exceeds that of BMI, it is the point of no return and death will occur within 1-2 months. Assuming such a trajectory, we reckon that when BMI and EI per BW reach critical levels, such as 18.0 and 29.2 or 17.3 and 28.3, respectively, the chance of survival diminishes dramatically.

It is considered necessary to maintain a constant EI as a measure to prevent the decrease in weight and BMI of elderly people who are admitted to an $\mathrm{NH}[38,39]$. Specifically, in the case of an elderly person with dementia who has not expressed an intention to end life care, a question of whether to implement $\mathrm{ANH}$ or not puts pressure on families and the $\mathrm{NH}$ staff [40-42]. According to the results of the present study, when BMI decreases regardless of sufficient EI per BW, despite the deficiency in EI being supplemented by additional energy intake, such as ANH, the maintenance of body weight or BMI is predicted to be difficult. We consider palliation to be the most important goal for institutionalized elderly people, and a decrease in EI following a decrease in BMI must be accepted as a transitional phenomenon to death.

The present study has certain limitations. First, the sample size was slightly small and limited to Japanese people from a single $\mathrm{NH}$; therefore, some results may only be applicable to the Japanese population. We also excluded elderly people who died within 6 months of being admitted to the $\mathrm{NH}$; thus, the results of this study cannot be applied to elderly people with acute diseases requiring continuous medical care or acute symptoms for which the $\mathrm{NH}$ could not provide adequate care.

Furthermore, the present study targeted all elderly people who lived and died in the $\mathrm{NH}$ under the same living conditions for approximately 13 years without $\mathrm{ANH}$. These elderly people mostly spent their time in a chair or on a bed and lacked the mobility or will to go to restrooms on their own. For 1 year prior to death, their BMIs dropped by a mean value of 2.0 accompanied by unintentional weight loss of approximately $5 \mathrm{~kg}$; thus, all the subjects in the present study were considered to be frail elderly individuals [43]. Therefore, mortality risks for frail elderly individuals with advanced dementia and debility not otherwise specified could be identified using the present results.

\section{Conclusion}

Dying institutionalized elderly people may have constant EI per BW values but decreasing BMIs from approximately 60 months prior to their death. Once such individuals reach a period of several months before death, EI per BW rapidly decreases. When the rate of decrease of EI per BW exceeds that of BMI, it is considered the point of no return and that death is imminent. Therefore, longitudinal observations of trajectories of BMI and EI over several months to years and the analysis of the relationship between these trajectories could identify mortality risks.

\section{Abbreviations}

BW: Body weight; BMI: Body mass index; El: Energy intake; $\mathrm{NH}$ : Nursing home; ANH: Artificial nutrition and hydration.

\section{Acknowledgments}

The authors would like to thank all the residents and the staff of the $\mathrm{NH}$. The authors thank Crimson Interactive Pvt. Ltd. (Ulatus) — www.ulatus.jp—for their assistance in manuscript translation and editing.

\section{Authors' contributions}

Y.K. obtained funding, designed and coordinated the study, performed data analysis, drafted the manuscript, and takes responsibility for the content. J.H. contributed to the design of the study and assisted with data analysis, supervising and drafting of the paper. All authors contributed to the intellectual content of the manuscript and have approved its final version. All authors have read and agreed to the published version of the manuscript. 


\section{Funding}

This work was supported by the 2018-2021 Ministry of Education, Culture, Sports, Science and Technology Grant-in-Aid for Scientific Research by Young Scientists [Research Project Number: 18K17623]. This research was completed independently from the funder. It had no role in the conceptualization of this study, nor in its design, analysis, data interpretation, or manuscript writing.

\section{Availability of data and materials}

The data cannot be shared publicly because there was no such approval in the study protocol. The datasets used and analyzed during the study are available from the corresponding author upon request and subject to ethical approval.

\section{Declarations}

\section{Ethics approval and consent to participate}

The study was planned and conducted in accordance with the principles of the Declaration of Helsinki, and the study protocol was approved by the Ethical Review Board of Tokyo Ariake University of Medical and Health Sciences (Project identification code: 256; date of approval: July 26, 2018). The requirement for informed consent was waived by the Ethics Committee of Tokyo Ariake University of Medical and Health Sciences because of the retrospective nature of the study and was not required for research that relied exclusively on secondary use of anonymous human biological materials as long as the process of data recording or dissemination of results does not generate identifiable information.

\section{Consent for publication}

Not applicable

\section{Competing interests}

The authors declare that they have no competing interests.

\section{Author details}

${ }^{1}$ Department of Nursing, Tokyo Ariake University of Medical and Health Sciences, Tokyo, Japan. ²Division of Clinical Medicine, Faculty of Medicine, University of Tsukuba, Tsukuba, Japan.

\section{Received: 16 August 2021 Accepted: 20 January 2022}

Published online: 31 January 2022

\section{References}

1. Mitchell SL, Kiely DK, Hamel MB, Park PS, Morris JN, Fries BE. Estimating prognosis for nursing home residents with advanced dementia. JAMA. 2004;291:2734-40.

2. Mitchell SL, Kiel DK, Hamel MB. Dying with advanced dementia in the nursing home. Arch Intern Med. 2004;164:321-6.

3. Toscani F, Finetti S, Giunco F, Basso I, Rosa D, Pettenati F, et al. The last week of life of nursing home residents with advanced dementia: a retrospective study. BMC Palliat Care. 2019;18:117

4. Van der Steen JT, Radbruch L, Hertogh CM, de Boer ME, Hughes JC, Larkin P, et al. White paper defining optimal palliative care in older people with dementia:A Delphi study and recommendations from the European Association for Palliative Care. Palliat Med. 2014;28:197-209.

5. Hebert RS, Schulz R, Copeland VC, Arnold RM. Preparing family caregivers for death and bereavement. Insights from caregivers of terminally ill patients. J Pain Symptom Manage. 2009;37:3-12.

6. Hebert RS, Dang Q, Schulz R. Preparedness for the death of a loved one and mental health in bereaved caregivers of patients with dementia: findings from the REACH study. J Palliat Med. 2006;9:683-93.

7. Cereda E, Zagami A, Vanotti A, Piffer S, Pedrolli C. Geriatric nutritional risk index and overall-cause mortality prediction in institutionalised elderly: a 3-year survival analysis. Clin Nutr. 2008;27:717-23.

8. Lukaszyk E, Bien-Barkowska K, Bien B. Identification of mortality risks in the advancement of old age: application of proportional hazard models based on the stepwise variable selection and the Bayesian model averaging approach. Nutrients. 2021;13:1098.
9. Porock D, Oliver DP, Zweig S, Rantz M, Mehr D, Madsen R, et al. Predicting death in the nursing home: development and validation of the 6-month minimum data set mortality risk index. J Gerontol. 2005;60A:491-8.

10. Sharifi F, Ghaderpanahi M, Fakhrzadeh H, Mirarefin M, Badamchizadeh Z, Tajalizadekhoob Y, et al. Older people's mortality index: development of a practical model for prediction of mortality in nursing homes (Kahrizak Elderly Study). Geriatr Gerontol Int. 2012;12:36-45.

11. Finucane AM, Bone AE, Etkind S, Carr D, Meade R, Munoz-Arroyo R, et al. How many people will need palliative care in Scotland by 2040? A mixedmethod study of projected palliative care need and recommendations for service delivery. BMJ Open. 2021;11:e041317.

12. Goldberg TH, Botero A. Causes of death in elderly nursing home residents. J Am Med Dir Assoc. 2008;9:565-7.

13. Shakersain B, Santoni G, Faxén-Irving G, Rizzuto D, Fratiglioni L, Xu W. Nutritional status and survival among old adults: an 11-year populationbased longitudinal study. Eur J Clin Nutr. 2016;70:320-5.

14. Gentile S, Lacroix O, Durand AC, Cretel E, Alazia M, Sambuc R, et al. Malnutrition: a highly predictive risk factor of short-term mortality in elderly presenting to the emergency department. J Nutr Health Aging. 2013;17:290-4.

15. Gomes F, Emery PW, Weekes CE. Risk of malnutrition is an independent predictor of mortality, length of hospital stay, and hospitalization costs in stroke patients. J Stroke Cerebrovasc Dis. 2016;25:799-806.

16. Sanders CL, Wengreen HJ, Schwartz S, Behrens SJ, Corcoran C, Lyketsos CG, et al. Nutritional status is associated with severe dementia and mortality: the Cache County Dementia Progression Study. Alzheimer Dis Assoc Disord. 2018;32:298-304

17. Murphy JL, Holmes J, Brooks C. Nutrition and dementia care: developing an evidence-based model for nutritional care in nursing homes. BMC Geriatrics. 2017;17:55.

18. Bamia C, Halkjaer J, Lagiou P, Trichopoulos D, Tjønneland A, Berentzen TL, et al. Weight change in later life and risk of death amongst the elderly: the European Prospective Investigation into Cancer and Nutrition-Elderly Network on Ageing and Health study. J Intern Med. 2010;268:133-44.

19. Lee IM, Paffenbarger RS Jr. Change in body weight and longevity. JAMA. 1992:268:2045-9.

20. Blair SN, Shaten J, Brownell K, Collins G, Lissner L. Body weight change, all-cause mortality, and cause-specific mortality in the Multiple Risk Factor Intervention Trial. Ann Intern Med. 1993;119:749-57.

21. Sergi G, Perissinotto E, Pisent C, Buja A, Maggi S, Coin A, et al. An adequate threshold for body mass index to detect underweight condition in elderly persons: the Italian Longitudinal Study on Aging (ILSA). J Gerontol A Biol Sci Med Sci. 2005;60:866-71.

22. Mazza A, Zamboni S, Tikhonoff V, Schiavon L, Pessina AC, Casiglia E. Body mass index and mortality in elderly men and women from general population. The experience of Cardiovascular Study in the Elderly (CASTEL). Gerontology. 2007;53:36-45.

23. De Stefani FD, Pietraroia PS, Fernandes-Silva MM, Faria-Neto J, Baena CP. Observational evidence for unintentional weight loss in all-cause mortality and major cardiovascular events: a systematic review and metaanalysis. Sci Rep. 2018;8:1-1.

24. Kawakami Y, Hamano J. Changes in body mass index, energy intake, and fluid intake over 60 months premortem as prognostic factors in frail elderly: a post-death longitudinal study. Int J Environ Res Public Health. 2020;17:1823

25. Tsutsui T, Muramatsu N. Care-needs certification in the long-term care insurance system of Japan. J Am Geriatr Soc. 2005;53:522-7.

26. Yokobayashi, K, Matsushima M. Fujinuma Y, Tazuma S. Retrospective cohort study of the incidence and risk of fever in elderly people living at home: A pragmatic aspect of home medical management in Japan. Geriatr Gerontol Int 2013;13:887-893.

27. Imahashi K, Kawagoe M, Eto F, Haga N. Clinical status and dependency of the elderly requiring long-term care in Japan. Tohoku J Exp Med. 2007:212:229-38.

28. NHS. Guidance on the Measurement and Estimation of Height and Weight. 2013. Available online: https://www.nhstaysidecdn.scot.nhs.uk NHSTaysideWeb/idcplg?ldcService=GET_SECURE_FILE\&Rendition= web\&RevisionSelectionMethod=LatestReleased\&noSaveAs=1\&dDocN ame=prod_217927. Accessed 27 July 2021.

29. Omura T, Tamura Y, Yamaoka T, Yoshimura Y, Sakurai T, Umegaki H, et al. Assessing the association between optimal energy intake and all-cause 
mortality in older patients with diabetes mellitus using the Japanese Elderly Diabetes Intervention Trial. Geriatr Gerontol Int. 2020;20:59-65.

30. Silver HJ, Wall R, Hollingsworth E, Pruitt A, Shotwell M, Simmons S. Simple $\mathrm{kcal} / \mathrm{kg}$ formula is comparable to prediction equations for estimating resting energy expenditure in older cognitively impaired long term care residents. J Nutr Health Aging. 2013;17:39-44.

31. Veronese N, De Rui M, Toffanello ED, De Ronch I, Perissinotto E, Bolzetta $F$, et al. Body mass index as a predictor of all-cause mortality in nursing home residents during a 5-year follow-up. J Am Med Dir Assoc. 2013;14:53-7.

32. Katano S, Yano T, Kouzu H, Ohori K, Shimomura K, Honma S, et al. Energy intake during hospital stay predicts all-cause mortality after discharge independently of nutritional status in elderly heart failure patients. Clin Res Cardiol. 2021;5:1-9.

33. Siervo M, Bertoli S, Battezzati A, Wells JC, Lara J, Ferraris C, et al. Accuracy of predictive equations for the measurement of resting energy expenditure in older subjects. Clin Nutr. 2014;33:613-9.

34. Buys DR, Roth DL, Ritchie CS, Sawyer P, Allman RM, Funkhouser EM, et al. Nutritional risk and body mass index predict hospitalization, nursing home admissions, and mortality in community-dwelling older adults: results from the UAB study of aging with 8.5 years of follow-up. J Gerontol A Biol Sci Med Sci. 2014;69:1146-53.

35. Söderström L, Rosenblad A, Adolfsson ET, Saletti A, Bergkvist L. Nutritional status predicts preterm death in older people: a prospective cohort study. Clin Nutr. 2014;33:354-9.

36. Bhaskaran K, dos-Santos-Silva I, Leon DA, Douglas IJ, Smeeth L. Association of the BMI with overall and cause-specific mortality: a population-based cohort study of 3.6 million adults in the UK. Lancet 2018;6(12):944-53.

37. Iyen B, Weng S, Vinogradova Y, Akyea RK, Qureshi N, Kai J. Long-term body mass index changes in overweight and obese adults and the risk of heart failure, cardiovascular disease and mortality: a cohort study of over 260,000 adults in the UK. BMC Public Health. 2021;21:576.

38. Wirth R, Streicher M, Smoliner C, Kolb C, Hiesmayr M, Thiem U, et al. The impact of weight loss and low BMI on mortality of nursing home residents-Results from the nutrition day in nursing homes. Clin Nutr. 2016;35:900-6.

39. Volker D, Beck AM, Cederholm T, Cruz-Jentoft A, Goisser S, Hooper L, et al. ESPEN guideline on clinical nutrition and hydration in geriatrics. Clin Nutr. 2019;38:10-47.

40. Pasman HRW, Onwuteaka-Philipsen BD, Ooms ME, van Wigcheren PT, van der Wal G, Ribbe MW. Forgoing artificial nutrition and hydration in nursing home patients with dementia: patients, decision making, and participants. Alzheimer Dis Assoc Disord. 2004;18:154-62.

41. Pasman HRW, Onwuteaka-Philipsen BD, Kriegsman DMW, Ooms ME, Ribbe MW, van der Wal G. Discomfort in nursing home patients with severe dementia in whom artificial nutrition and hydration is forgone. Arch Intern Med. 2005;165:1729-35.

42. Pasman HRW, Onwuteaka-Philipsen BD, Kriegsman DMW, Ooms ME, Ribbe MW, Van der Wal G. Degree of discomfort following the decision to discontinue artificial nutrition and hydration in institutionalised psychogeriatric patients with severe dementia who no longer or scarcely eat or drink. Ned Tijdschr Geneeskd. 2006;150:243-8.

43. Fried LP, Tangen CM, Walston J, Newman AB, Hirsch C, Gottdiener J, et al. Frailty in older adults: evidence for a phenotype. J Gerontol A Biol Sci Med Sci. 2001;56:M146-56.

\section{Publisher's Note}

Springer Nature remains neutral with regard to jurisdictional claims in published maps and institutional affiliations.

Ready to submit your research? Choose BMC and benefit from:

- fast, convenient online submission

- thorough peer review by experienced researchers in your field

- rapid publication on acceptance

- support for research data, including large and complex data types

- gold Open Access which fosters wider collaboration and increased citations

- maximum visibility for your research: over $100 \mathrm{M}$ website views per year

At BMC, research is always in progress.

Learn more biomedcentral.com/submissions 